\title{
Transcriptional regulation of FABP expression in flight muscle of the desert locust, Schistocerca gregaria
}

\author{
Jun Zhang, Norbert H. Haunerland * \\ Department of Biological Sciences, Simon Fraser University, Burnaby, B.C., Canada V5A IS6
}

Received 5 January 1998; accepted 20 April 1998

\begin{abstract}
FABP is the most abundant cytosolic protein in developed flight muscle of adult locusts, but it is completely absent in nymphs. During the two weeks following adult ecdysis, FABP rises to $18 \%$ of the total soluble proteins. Its mRNA increases steadily up to day 8 , before it gradually declines until reaching a low concentration at day 15, which remains constant for the rest of the animal's life. Using a PCR primer combination specific for a 597 bp sequence of intron 1, we have developed a reverse transcription PCR assay to quantify the amount of primary transcript present in muscle tissue at various ages. The FABP gene is not transcribed prior to metamorphosis; its primary transcript rises rapidly during the first two days of adult life, and remains close to maximal until day 5. Subsequently its level rapidly declines, ultimately reaching values of less than $0.02 \%$ of the maximal level. The correlation between primary transcript, mRNA and FABP content were analyzed by modeling transcription, translation and degradation with computer modeling software. The computer simulation is in good agreement with the experimentally obtained data, suggesting that the control of FABP expression in locust flight muscle occurs predominantly at the level of transcription initiation. (C) 1998 Elsevier Science Ltd. All rights reserved.
\end{abstract}

Keywords: Fatty acid binding protein; Quantitative PCR; RT-PCR; Computer simulation; Gene Expression; Nuclear RNA

\section{Introduction}

Like most other muscles engaged in sustained activity, the flight muscle of the desert locust depends on fatty acid oxidation as an energy source for migratory flight. During flight, diacylglycerol is released from the fat body and transported through the hemolymph by lipophorin. Following hydrolysis at the sarcolemma, free fatty acids enter the flight muscle cells, where their ultimate fate is mitochondrial beta-oxidation (for a recent review, see Haunerland, 1997). Due to their low water solubility, fatty acids require a transport mechanism for their efficient translocation through the aqueous cytosol. This intracellular transport appears to be mediated by FABP (fatty acid binding protein, Haunerland and Chisholm, 1990; Van der Horst et al., 1993), a small cyto-

Abbreviations: FABP, fatty acid binding protein; IS, internal standard; LP, lower primer; PCR, polymerase chain reaction; RT-PCR, reverse transcription polymerase chain reaction; UP, upper primer.

*Corresponding author. Tel: + 1-604-291-3734; Fax: + 1-604-2913496; E-mail: haunerla@sfu.ca solic protein that is abundant in the muscle of adult locusts.

The FABP from locust muscle is very similar to the fatty acid binding proteins that have been found in vertebrate muscles, both in structure and function (Veerkamp and Maatman, 1995; Haunerland et al., 1992; Haunerland, 1994). The FABP concentration in a given muscle seems to reflect its fatty acid oxidation capacity, and hence the highest levels of the protein are found in muscles that utilize predominantly fatty acid as energy source (Veerkamp and van Moerkerk, 1993). In mammals, cardiac muscle contains most FABP, which accounts for up to $6 \%$ of all cytosolic proteins. As flight muscles of birds and locusts can sustain fatty acid-fueled metabolic rates two or three times as high, respectively (Crabtree and Newsholme, 1975), their FABP content is also elevated by similar factors (Chen et al., 1993; Guglielmo et al., 1998). In mature locusts, FABP comprises up to $20 \%$ of all soluble muscle proteins. However, FABP is absent in the mesothorax muscles of locust nymphs, which do not possess wings and consequently are unable to fly (Haunerland et al., 1992). FABP 
begins to accumulate within two days after metamorphosis, and reaches its maximum after two weeks. Subsequently, its concentration remains constant.

The protein was never detected in nymphs, even when the last nymphal stage was extended by 30 days through treatment with the molting inhibitor azadirachtin, or when a supernumerary molt was induced with a juvenile hormone analog (Chen and Haunerland, 1994). In contrast, FABP levels in precocious adults, developed after ethoxy-precocene treatments, resembled closely those found in normal adults, indicating that FABP is a strictly adult specific protein.

FABP mRNA is also absent in nymphs. It becomes first detectable immediately after adult ecdysis and increases steadily for about six days. The mRNA levels then remain constant for several days, before gradually decreasing to a low, constant level that is reached just when the FABP concentration is maximal (day 15). This low level appears to be sufficient to replace degrading protein, so that the established FABP level is held constant (Haunerland et al., 1992).

While the observed induction of FABP expression after metamorphosis is not unexpected for an adult specific protein, the drop in FABP mRNA several days later is less easily understood. Apparently, the high levels of mRNA during the first few days of adulthood are required to assure that FABP accumulates quickly; once FABP approaches its maximum, much smaller amounts of mRNA are required. Possibly, a reduction in the transcription of the FABP gene is responsible for the observed changes in mRNA; alternatively, this could be caused by altered mRNA stability, while the expression of the gene remains unchanged. In order to decide whether this feedback is at the transcriptional level, it is necessary to measure FABP transcription itself, and link it to the levels of mRNA found.

Commonly, nuclear run-on assays have been employed to analyze transcription in differentiated tissues (Marzluff and Huang, 1984). While providing valuable indicators for the ongoing transcription rates, this method has been found to be fairly insensitive and difficult to perform in muscle tissue (McCully and Liew, 1988; Carey et al., 1994). Moreover, since the run-on reaction is carried out after the time-consuming isolation of nuclei, it can be questioned whether this technique can really provide insight into the events that happen in vivo.

The small size of flight muscles in locusts is an additional limitation, making it difficult to isolate sufficient number of nuclei for this assay. Indeed, numerous attempts in our laboratory have failed to produce reliable results with run-on assays from locust flight muscle, and therefore we have sought an alternative method for measuring FABP transcription that offers higher sensitivity. The amount of primary transcript present in a cell provides a good measure for the ongoing transcription rate, since unprocessed RNA always has a very short halflife (Elferink and Reiners, 1996; Hargrove, 1993). In this paper, we describe the quantitative determination of FABP primary transcript by quantitative RT-PCR, and discuss the correlation between expression rate, mRNA and FABP content during adult muscle development.

\section{Materials and methods}

\subsection{Insects}

Locusts (Schistocerca gregaria) were reared in crowded conditions at $32^{\circ} \mathrm{C}$ under continuous light. Last instar stage nymphs were collected and raised separately. The mesothorax muscle of nymphs within $24 \mathrm{~h}$ before adult ecdysis were dissected and total RNA was isolated immediately. To determine FABP expression in adult locusts, freshly emerged adults were removed and reared separately until sacrificed for RNA analysis at the specified age. Individuals between 0 and 24 hours after adult molting are referred to as day 1 adults, with each subsequent day representing an additional 24 hour period.

\subsection{RNA isolation}

Unless otherwise specified, all chemicals were purchased from Gibco BRL Life Technology (Burlington, $\mathrm{ON})$. Freshly excised flight muscle tissue was homogenized immediately in extraction buffer ( $4 \mathrm{M}$ guanidinium isothiocyanate, $25 \mathrm{mM}$ sodium citrate $\mathrm{pH} 7.0,0.5 \%$ sarcosyl, $0.1 \mathrm{M}$ 2-mercaptoethanol) with a mechanical homogenizer. Total RNA was isolated by a one step guanidinium isothiocyanate/phenol/chloroform extraction method adapted from Chomczynski and Sacchi (1987) $($ O.D ratio $(260 \mathrm{~nm} / 280 \mathrm{~nm})=2.0)$. For each data point, the total RNA from each of five individuals was combined into a single sample. The absence of genomic DNA was confirmed by PCR carried out with the same primers and under identical conditions as described below, with the exception that the reverse transcription reaction was omitted. All samples were stored in $100 \%$ ethanol at $-80^{\circ} \mathrm{C}$ until used. At that time, the absence of genomic DNA was confirmed for each sample by PCR.

\subsection{PCR primer design}

PCR primers were designed from $2 \mathrm{~kb}$ of $3^{\prime}$ sequence of the first intron of the locust FABP gene, which interrupts the coding sequence at the Gly 27 codon (Haunerland et al., unpublished results; see Fig. 1). The upper primer (UP) (5' AAG CAA CAC ATC TCC AGA ATC $3^{\prime}$ ) and lower primer (LP) (5' CAA ATT ACA CTA GCA TCT CAG 3') flanked a 555 bp fragment which ends $1722 \mathrm{bp}$ upstream of the second exon. PCR 


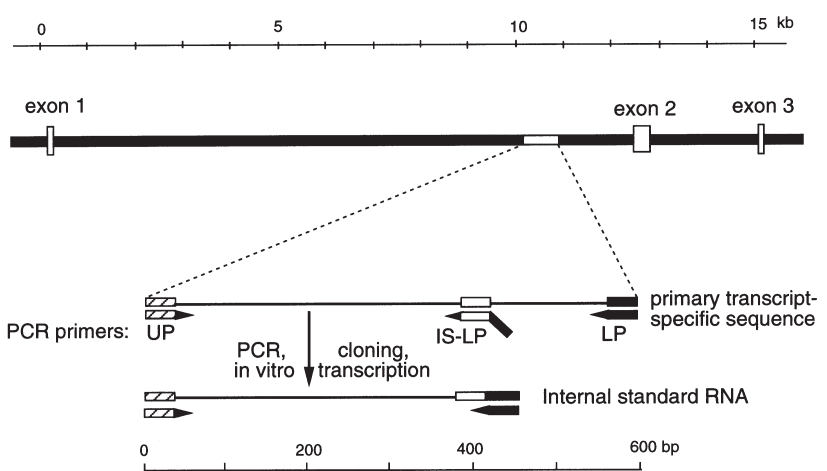

Fig. 1. Construction of the internal standard RNA for RT-PCR. A $597 \mathrm{bp}$ fragment located within the first intron of the locust FABP gene was amplified by PCR. A $441 \mathrm{bp}$ fragment was amplified from the PCR product, using the same upper primer and a 42 bp lower primer whose 3' 21 nucleotides annealed to a sequence string 400 bp downstream of the upper primer site. The $5^{\prime} 21$ nucleotides of the lower primer were identical to the original lower primer, so that the product can be amplified with the same primers that produce the $597 \mathrm{bp}$ band. Details see Materials and Methods.

with genomic DNA as template yielded a $600 \mathrm{bp}$ product $($ expected fragment size $=597 \mathrm{bp})$.

\subsection{Quantitative reverse transcription polymerase chain reaction $(Q-R T-P C R)$}

Thawed RNA samples were centrifuged at $4^{\circ} \mathrm{C}$ for 20 min at $10,000 \mathrm{~g}$, washed with $70 \%$ cold ethanol and dried in a Speed-vac system (Savant, Holbrook, NY). The dried RNA pellets were dissolved in RNase-free $\mathrm{H}_{2} \mathrm{O}$ and the RNA concentration adjusted to $3 \mu \mathrm{g} / \mu \mathrm{l}$.

Reverse transcription PCR was performed according to the manufacturer's instructions with the GeneAmp RNA PCR Kit (Perkin-Elmer, Foster City, CA) in a GeneAmp PCR System 2400. Reverse transcription was carried out from the intron specific lower primer $\left(5^{\prime}\right.$ CAAATTACACTAGCATCTCAG 3'). The $20 \mu \mathrm{l}$ reaction mixture contained $1 \times$ PCR buffer II, $5 \mathrm{mM} \mathrm{MgCl}$, $1 \mathrm{mM}$ each of deoxy nucleoside triphosphate, $1 \mathrm{U}$ of RNase inhibitor, $2.5 \mathrm{U}$ of MuLV reverse transcriptase, $2.5 \mu \mathrm{M}$ lower primer, and between $3 \mathrm{ng}$ and $3 \mu \mathrm{g}$ total RNA. For quantitative RT-PCR reactions, between 1.3 $\times 10^{5}$ and $1.3 \times 10^{7}$ molecules of the internal standard RNA were also added. Following incubation for $10 \mathrm{~min}$ at $25^{\circ} \mathrm{C}$ and $60 \mathrm{~min}$ at $42^{\circ} \mathrm{C}$, the reaction was terminated by heating to $100^{\circ} \mathrm{C}$ for $5 \mathrm{~min}$ and cooling to $4^{\circ} \mathrm{C}$.

The reverse transcription product was added immediately to $80 \mu \mathrm{l}$ PCR reaction mixture contained $2 \mathrm{mM}$ $\mathrm{MgCl}_{2}, 1 \times$ PCR buffer II, $0.5 \mu \mathrm{M}$ upper primer, and $2.5 \mathrm{U}$ AmpliTaq DNA polymerase. The mixture was denatured at $95^{\circ} \mathrm{C}$ for $105 \mathrm{~s}$ and amplified for 30 cycles of $10 \mathrm{~s}$ at $95^{\circ} \mathrm{C}, 30 \mathrm{~s}$ at $50^{\circ} \mathrm{C}, 30 \mathrm{sec}$ at $68^{\circ} \mathrm{C}$. Following $7 \mathrm{~min}$ at $68^{\circ} \mathrm{C}$, the reaction mixture was cooled down to $4^{\circ} \mathrm{C}$. The PCR product $(10 \mu \mathrm{l})$ was analyzed on a $2.0 \%$ agarose gel stained with ethidium bromide.

\subsection{Synthesis of internal standard template plasmid}

In order to produce an internal standard molecule that, when amplified with the same primers as the intron sequence, yielded an amplification product of a distinguishably smaller size (Celi et al., 1993), a hybrid lower primer was constructed (IS-LP) (5' CAA ATT ACA CTA GCA TCT CAG TGA GCT CTC GAA GTA TGA TAG 3') (Fig. 1). Its 3' 21 nucleotides annealed to a sequence string $177 \mathrm{bp}$ upstream of the original lower primer, while the 21 nucleotides at its $5^{\prime}$ end were identical to the sequence of the original lower primer. The primer contains also an XhoI restriction site (GAGCTC). With genomic DNA as template, a $441 \mathrm{bp}$ fragment (ISDNA, internal standard DNA) was amplified after PCR $\left(105 \mathrm{~s}\right.$ at $95^{\circ} \mathrm{C}, 35$ cycles of $10 \mathrm{~s}$ at $95^{\circ} \mathrm{C}, 30 \mathrm{~s}$ at $51.5^{\circ} \mathrm{C}$, $30 \mathrm{~s}$ at $68^{\circ} \mathrm{C}, 7 \mathrm{~min}$ at $68^{\circ} \mathrm{C}$, final temperature $4^{\circ} \mathrm{C}$ ) with the primer pair UP and IS-LP. The amplification product was directly cloned into PCR-II vector (TA cloning kit, Stratagene, La Jolla, CA). After cleaving the vector with EcoRI, the insert was gel purified and ligated into a Bluescript vector (Bluescript KS, Stratagene, La Jolla, CA). Plasmid DNA was digested with XhoI to select plasmids where the insert was downstream of the T7 promoter, and the insert identity was confirmed by PCR.

\subsection{In vitro transcription of the internal standard sequence}

Internal standard RNA was produced with the MAXIscript in vitro transcription kit (Ambion, Austin, TX). Between 0.5 and $1 \mu \mathrm{g}$ of the HindIII-linearized, gel purified internal standard plasmid was added to $2 \mu \mathrm{l} 10 \times$ buffer, $1 \mu \mathrm{l}$ each of $10 \mathrm{mM}$ nucleoside triphosphate, $5 \mathrm{U}$ RNase inhibitor, 5 U T7 RNA polymerase, and the mixture was brought up to a volume of $20 \mu \mathrm{l}$ with diethylpyrocarbonate treated water. Following in vitro transcription for $1 \mathrm{~h}$ at $37^{\circ} \mathrm{C}$ the DNA template was removed by DNase I digestion ( $2 \mathrm{U}$ of RNase free DNase $30 \mathrm{~min}$ at $37^{\circ} \mathrm{C}$ ) (Ambion, Austin, TX); subsequently, the sample was kept at $100^{\circ} \mathrm{C}$ for 5 min to denature the enzymes. The resulting RNA was precipitated with ethanol, quantified spectrophotometrically, and checked by PCR for the absence of DNA contamination. The RNA was kept at $-80^{\circ} \mathrm{C}$ in aliquots for single use.

\subsection{Detection and quantitation of PCR products}

Constant numbers of molecules of internal standard RNA were added to decreasing amounts of RNA samples, and both template and standard RNA competed for the PCR primers in the RT-PCR reaction. Ethidium bromide stained gels of the amplification products were visualized on a UV transilluminator and documented with a UVP5100 camera system (UVP, San Gabriel, $\mathrm{CA})$. Images were saved as TIFF files and analyzed on 
a Macintosh computer with the Image software package (version 1.61b7, NIH, Bethesda, MD). The ratio of the densities measured for the template and internal standard bands was plotted against the amount of total RNA used as template on a double logarithmic scale. As the $597 \mathrm{bp}$ PCR product of the template is $35 \%$ larger than the $441 \mathrm{bp}$ internal standard, a ratio of 1.35 indicates an equal number of template and internal standard.

\subsection{Computer simulation}

Data were analyzed by computer simulation (Hargrove, 1994) with the Software package STELLA II (version 4.0, High Performance System, Hanover, $\mathrm{NH}$ ). A two-compartment model of FABP gene expression was constructed, assuming zero-order synthesis and first order decay for mRNA and FABP. mRNA synthesis was treated as a function of the primary transcript concentration measured, and protein synthesis as function of the mRNA concentration. All data were expressed relative to the maximal value encountered. Primary transcript was maximal at day $5(100 \%=$ 520,000 copies/ng RNA), mRNA peaked at day 8 (100\% $=$ FABP mRNA/actin mRNA 5.0), while FABP reached its maximal value after day $15(100 \%=18 \%$ of total cytosolic proteins) (Haunerland et al., 1992).

The model was defined by the following equations and parameters:

$\operatorname{mRNA}(\mathrm{t})=\operatorname{mRNA}(\mathrm{t}-\mathrm{dt})+($ processing/transport RNA—decay) * dt; intial mRNA = 0 ; processing/transport $\quad=\quad \mathrm{V}_{\max } *$ (primarytranscript/(primary-transcript $\left.\left.+\mathrm{K}_{\mathrm{M}}\right)\right)$. $\mathrm{FABP}(\mathrm{t})=$ FABP $(\mathrm{t}-\mathrm{dt})+($ mRNA-FABP-decay $) * d t$; intial FABP $=0$;

The values for the primary transcript concentration (\% of maximum) were entered in step-gradients: primarytranscript $=0+\operatorname{STEP}(1.4$, day 1$)+\operatorname{STEP}(21.54$, day 2$)$ $+\operatorname{STEP}(47.89$, day 3) + $\operatorname{STEP}(29.67$, day 5)$\operatorname{STEP}(74.39$, day 6)-STEP(18.40, day 8)-STEP(0.34, day 10)-STEP(0.14, day 12$)-\operatorname{STEP}(0.05$, day 20$)$

The best match between the simulated values for mRNA and protein and the previously measured data (Haunerland et al., 1992) was obtained when using the following parameters: RNA-decay $=0.347 *$ mRNA; $\mathrm{FABP}$-decay $=0.023^{*} \mathrm{FABP} ; \mathrm{V}_{\max }=41 \%$ /day; $\mathrm{K}_{\mathrm{M}}=$ 2000 copies/ng RNA (0.38\% of maximum).

\section{Results}

\subsection{PCR from genomic DNA}

The primers designed in this study are specific to the sequence in intron 1 of the locust flight muscle FABP gene and work well for the PCR amplification of the enclosed sequence. PCR with primers UP and LP and genomic DNA as template resulted in a single PCR product of approximately $600 \mathrm{bp}$, virtually identical to the expected size (597 bp) (Fig. 2). The same fragment was obtained when using reverse transcribed total RNA extracted from flight muscle of 5 day old adult locusts as a template, indicating that primary transcript is indeed present at this stage.

In order to examine whether competitive PCR with these primers was feasible to obtain quantitative data, a constant number of cloned internal standard DNA was used together with varying amounts of target DNA as templates for competitive PCR. As expected, the band intensities changed with varying ratios of target and standard. Quantitative evaluation by image analysis revealed that when equal numbers of target and standard DNA had been used as template for the PCR reaction, a target to standard band intensity ratio of 1.34 was obtained (data not shown). This confirmed that equal amounts of both PCR products had been produced since the PCR product amplified from target DNA is 35\% larger and hence will stain more intensely with ethidium bromide.

\subsection{PCR from total RNA}

The internal standard RNA, when used as template for RT-PCR, resulted in the expected amplification product of $441 \mathrm{bp}$. No band was detected in a control experiment that omitted the reverse transcription step, proving that the RNA was indeed free of DNA contamination (Fig. 2).

In order to investigate the developmental changes of FABP primary transcripts, total RNA was isolated from flight muscles at various time points during the first 20

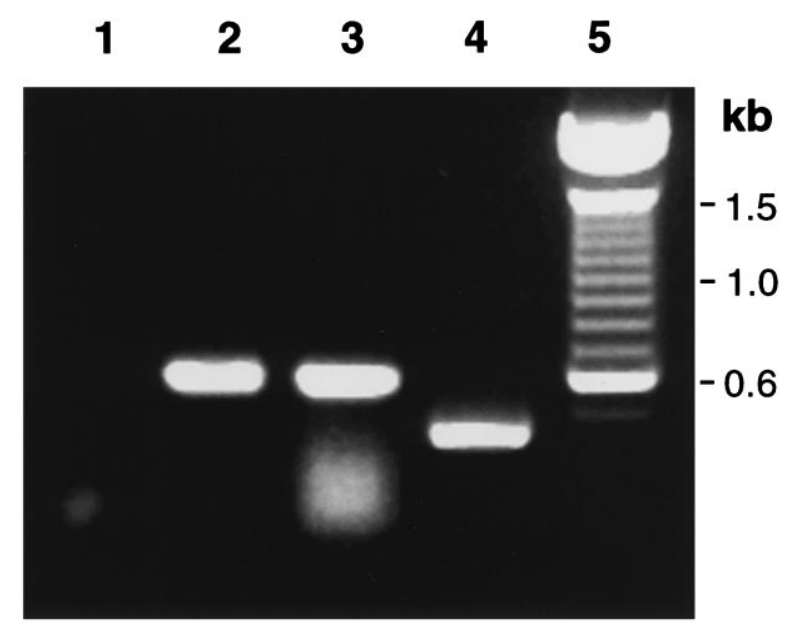

Fig. 2. PCR of target and standard sequences. Samples were amplified by PCR with primers specific for the $597 \mathrm{bp}$ sequence string in the first intron of the FABP gene. Lane 1: Template: total RNA from 5 day old adults, no reverse transcription reaction. Lane 2: Template: genomic DNA from adult locusts. Lane 3: Template: total RNA from 5 day old locusts after reverse transcription. Lane 4: Template: internal standard RNA after reverse transcription. Lane 5: size markers. 
days after adult ecdysis, and the primary transcript levels were analyzed with reverse transcription PCR. Initially, the reactions were carried out without internal standard. While these results do not allow quantitation, it is clear that dramatic changes occur during muscle development (Fig. 3). In flight muscle of 5th instar nymphs, no FABP primary transcript was detectable even when more than $3 \mu \mathrm{g}$ of total RNA were used as a template. A strong band representing the amplification product of the primary transcript is visible in 2 day old adults. While the band appeared even more intense in 5 day old adults, it was considerably weaker in 10 day old insects and weak, but still clearly detectable in 20 day old adults.

\subsection{Quantitative RT-PCR}

For the quantitation of these changes, series of RTPCR reactions with varying concentrations of target RNA were carried out in the presence of known amounts of internal standard RNA. As the amount of total RNA that can be used as template is limited to a range between $2 \mathrm{ng}$ and $3 \mu \mathrm{g}$, the number of standard molecules had to be adjusted so that equal numbers of target and standard were present within this range. In 2 to 6-day-old locusts, where the largest number of primary transcript template was present, $1.3 \times 10^{7}$ molecules of internal standard RNA were used in each reaction. For 8-day-old locusts, $1.3 \times 10^{6}$ molecules were used, while for day 1 and 10 , 12, 20-day-old locusts, $1.3 \times 10^{5}$ molecules of internal standard RNA were included in each reaction. With these adjustments, the target to standard band intensity ratios always covered at least the range of 0.5 to 1.5 .

The results for day 5 are shown in Fig. 4. The density ratio between the target bands to the internal standard bands was plotted on a double logarithmic scale against the amount of total RNA used. Since the target PCR product is $35 \%$ larger than the standard product, the

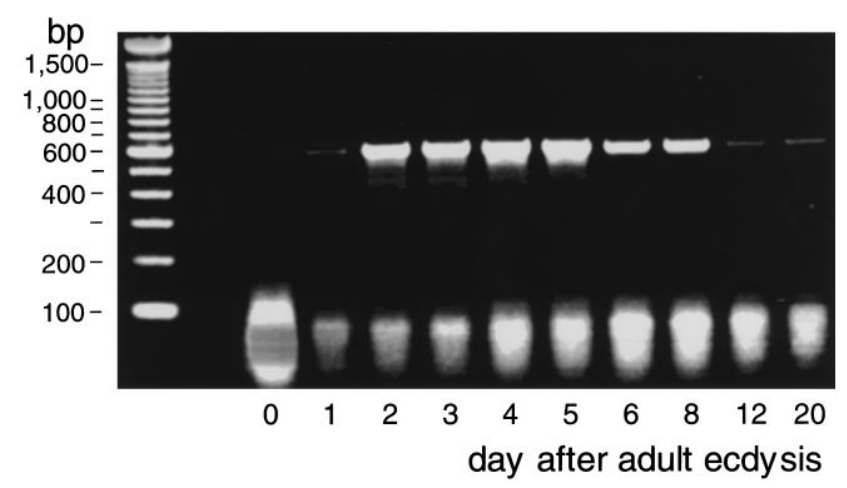

Fig. 3. RT-PCR from total RNA during adult development. Total RNA (3 $\mu \mathrm{g}$ each), isolated from locusts at the specified age, was reverse transcribed and amplified by PCR with primers specific for a 597 bp sequence string in the first intron of the FABP gene. Day $0=$ locusts nymphs sacrificed within 12 hours prior to metamorphosis. Day 1: adult locusts sacrificed within the first 12 hours after adult ecdysis. Each additional day represents an additional 24 hour period.

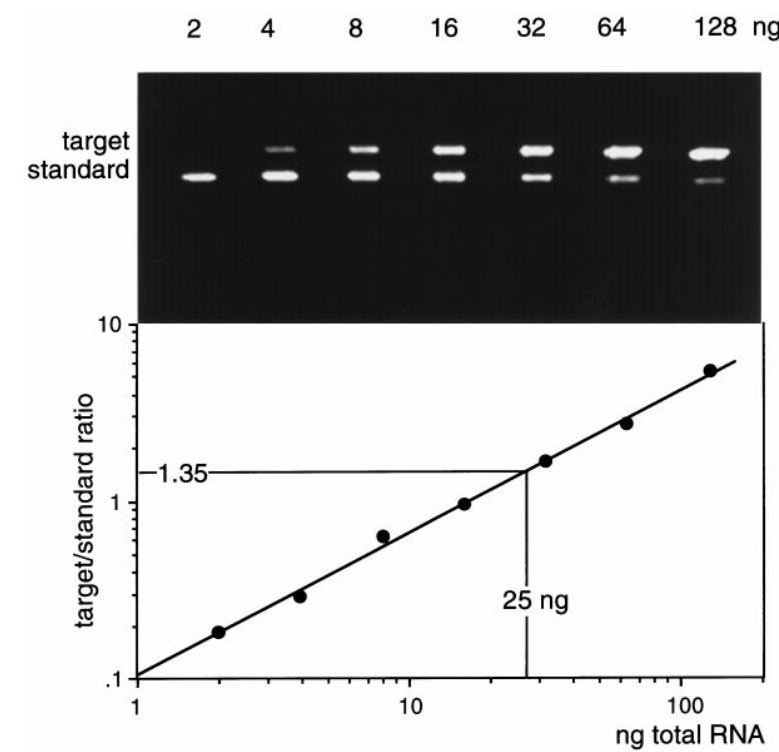

Fig. 4. Quantitation of FABP primary transcript in 5 day old locusts. Varying amounts of total RNA, as indicated, were mixed with $1.3 \times$ $10^{7}$ molecules of internal standard RNA, and amplified by RT-PCR as described in Materials and Methods. The same number of the $597 \mathrm{bp}$ target as the $441 \mathrm{bp}$ standard used are present in $25 \mathrm{ng}$ of total RNA, when the PCR products are present at equal amounts, i.e. when the band intensity ratio is $597 / 441=1.35$. Thus, the primary transcript concentration in 5 day old adults is 520,000 molecules/ng total RNA.

numbers of target molecules and internal standard are identical when the target to standard intensity ratio is 1.35. From this point, the primary transcript copy number per ng RNA was calculated. In 5-day-old locust flight muscle, $1.3 \times 10^{7}$ molecules of target RNA were present in $25 \mathrm{ng}$ of total RNA; hence, the primary transcript concentration was 520,000 copies/ng of total RNA.

Similar experiments were carried out at other days of development (Fig. 5). The transcript numbers were similar in 2 to 5 day old insects, but much smaller at day 8 . The concentration continued to decline over the next few days. At day 20, FABP primary transcript was still detectable, but at less than $0.01 \%$ of the value found at day 5. No primary transcript was detectable in insects immediately before metamorphosis, even in $3 \mu \mathrm{g}$ of total RNA, when only $10^{4}$ molecules of standard were used. Therefore, if the FABP gene was transcribed at all, it would be at a very low rate, resulting in less than 3 molecules of primary transcript per ng of total RNA.

\section{Discussion}

In the current study, we have developed a method to quantitatively study the rate of gene expression in a differentiated muscle by measuring the accumulation of primary transcript of the FABP gene with a competitive quantitative PCR assay. As the times for RNA pro- 


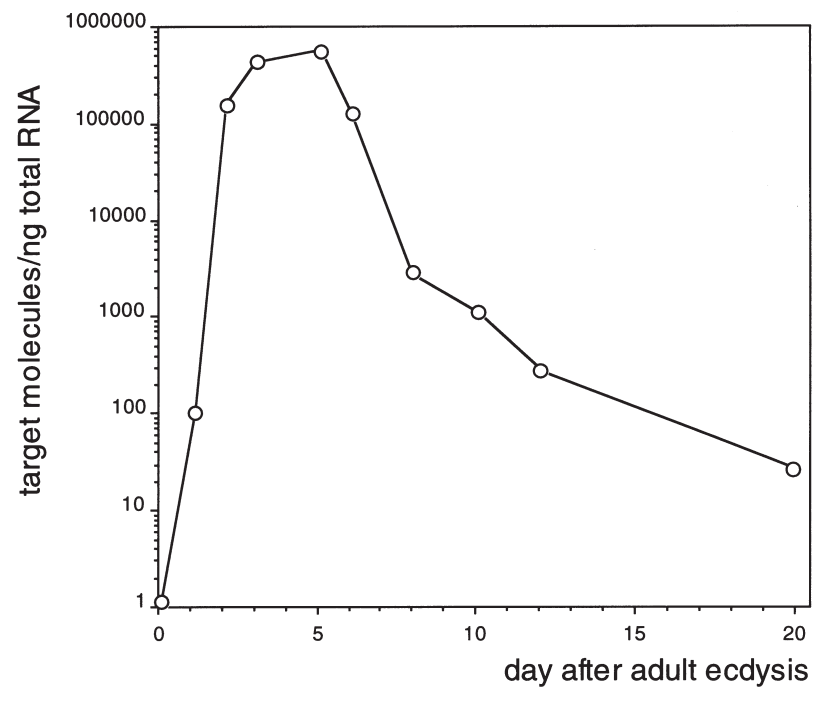

Fig. 5. Developmental profile of FABP expression. The concentration of FABP primary transcript molecules was determined by RTPCR at the indicated times during adult development, as illustrated in Fig. 4. Details see Materials and Methods.

cessing in the nucleus and its transport into the cytosol are normally very short, the number of unspliced RNA molecules provides a good measure for the actual transcriptional activity, as recently shown by Elferink and Reiners (1996). In contrast to run-on assays which require tissue disruption and lengthy purification of nuclei prior to measuring transcriptional activity, this method allows the determination of transcriptional rates present in vivo. Moreover, it is far more sensitive than nuclear run-on analysis. In order to isolate the $10^{7}$ nuclei that are needed for run-on transcription, more than $10 \mathrm{~g}$ of muscle tissue were required. In contrast, fewer than 10,000 molecules of primary transcript can be detected in $3 \mu \mathrm{g}$ of total RNA, which can be easily isolated from less than $100 \mathrm{mg}$ of tissue.

Our data clearly show that the observed pattern of FABP mRNA and protein accumulation during adult development of the locust is the consequence of changes in transcription of the FABP gene. The FABP gene is not transcribed at detectable levels prior to metamorphosis, even though the muscle is already mostly differentiated (Broesemer et al., 1963; Wang et al., 1993). Although transcription occurs immediately after metamorphosis, the number of transcript molecules is relatively low at the first day, indicating a delay in full activation due to the need to synthesize other factors required for optimal transcription. From day 2 to day 5, the transcript number increases several 1000-fold. Although the measured numbers cannot be seen as exact values, as the intrinsic errors due to the exact quantitation or large dilution may result in considerable variations, it is clear that the gene is transcribed at very high rates until day 6. In 5 day-old adult locusts, the FABP primary transcript reached its peak with more than
500,000 copies in one ng total RNA. Assuming that each copy detected here represents the full $15 \mathrm{~kb}$ primary transcript, FABP primary transcript accounts for $0.1 \mathrm{pg}$ of RNA, or approximately $0.01 \%$ of the total RNA. These large amounts of primary transcript are present at a time when FABP mRNA levels are still increasing; at day 5, mRNA has reached approximately $90 \%$ of its peak level (Haunerland et al., 1992), while only one third of the final FABP has accumulated. Subsequently, the concentration of primary transcript declines rapidly. At day 8, when FABP mRNA is still near its maximum, its primary transcript level is reduced to approximately 2000 molecules per ng total RNA, and between day 15 and 20 only 200 copies or less were detected. At this time, FABP has reached its maximum, and its mRNA has returned to a constant level of approximately $15 \%$ of its maximum. In contrast to the mRNA levels, the primary transcript has changed by a much larger factor to less than $0.1 \%$ of their maximal levels. As the primers used are both contained within an intron sequence, it could be possible that this sequence serves as template for the RT-PCR reaction even after it has been removed from the primary transcript. This would influence the results only if the resulting lariat is very stable. Generally, spliced intron sequences are believed to be rapidly degraded (Sharp, 1994), but isolated examples exist where lariats accumulate in the nucleus (Quian et al., 1992). Considering the precipitous decline in template molecules after day 5, however, it is apparent that the unknown half-life of the primary transcript and the spliced lariat can be neglected in the data analysis, as both must be much shorter than that of the mRNA.

The data can be used to estimate the stability of both mRNA and FABP. After day 12, the mRNA value is stable at around $15 \%$ of its maximum, and primary transcript is very low, between 50 and 300 copies (0.01$0.06 \%$ of its maximum value). Considering the inaccuracies of these values, an approximate value of $0.05 \%$ was chosen. If $0.05 \%$ of maximal primary transcript can account for replacing the proportion of the constant mRNA pool that breaks down, then $100 \%$ primary transcript should lead to a 2000-times larger synthesis rate. That would be consistent with the observed mRNA pattern only if the mRNA was extremely stable. However, the decline of mRNA between day 12 and 15 suggests that the half-life cannot be much larger than 2 days, as during this period the mRNA values are cut in half every two days. Moreover, mRNA still increases between day 6 and day 8, although its primary transcript values have declined to between 20 and $5 \%$ of its maximum. It is thus obvious that the relationship between primary transcript and protein is not linear, at least not over the entire 20 days.

A two compartment model describing the relationship between primary transcript, mRNA, and FABP was constructed (Fig. 6), and computer simulation was carried 


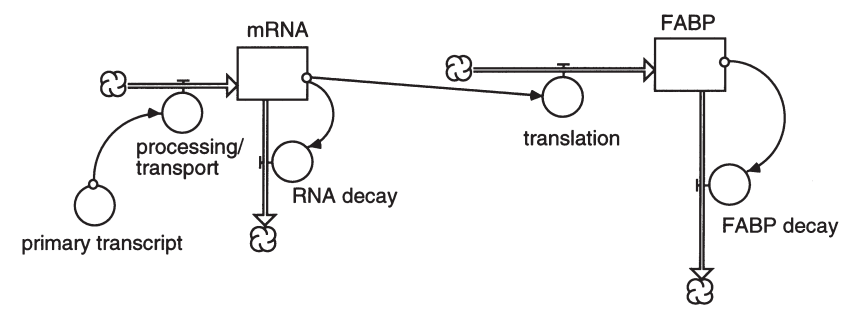

Fig. 6. Computer model of FABP expression. The model depicts how FABP, its mRNA and its primary transcript are connected. The FABP concentration found in the muscle depends on FABP degradation (1st order dependency of FABP) and synthesis (proportional to mRNA); mRNA depends on degradation (1st order dependency of mRNA) and its transport from the nucleus into the cytosol, which in turn depends on the concentration of primary transcript found in the nucleus. Computer simulation allows to modify the rates of degradation, synthesis and processing until the best fit between measured and simulated data is obtained.

out with varying parameters until a good match between the simulated and previously measured data (Haunerland et al., 1992) was reached. Initially, the simulation was carried out only between day 8 and 20, where primary transcript values are low, so that a linear relationship between primary transcript and mRNA can be assumed. For this period, the best match between the simulated and measured values was obtained when assuming an mRNA half-life of 2.3 days.

Substrate saturation may occur when the primary transcript is present in large amounts (Hargrove, 1994). Processing and transport involve enzymatic reactions that should behave according to normal enzyme kinetics that can be described by the Michaelis-Menten equation. Many enzyme reactions and the transport out of the nucleus into the cytosol are involved in the conversion from primary transcript to mRNA; for the purpose of the simulation these can be all considered as one process. Optimal match between the measured data and the simulated values was obtained for a $K_{M}$ value of $0.2 \%$ (Fig. 7 ). This means that at the concentration of 1030 copies of primary transcript/ng of RNA $(0.2 \%$ of the maximal value of 520,000 found on day 5), the mRNA synthesis/export rate is half of the maximal rate. As the primary transcript concentration increases, the mRNA synthesis rate approaches a maximum, while at lower primary transcript concentration the synthesis of mRNA is almost proportional to the amount of primary transcript present.

The rate of FABP translation appears to be proportional to the amount of mRNA present, as observed in many other systems (Palmiter, 1973; Pelham and Jackson, 1976; Richter and Smith, 1981). Assuming that the low mRNA level present in fully grown, mature adults is sufficient for the replacement of decaying FABP, the half-life of FABP can be estimated from the mRNA and FABP values measured. The accumulation of FABP can be best simulated from the mRNA values

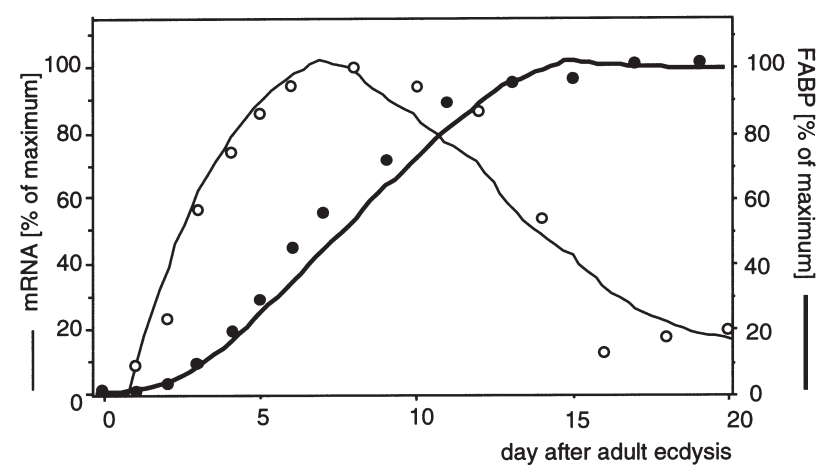

Fig. 7. Computer simulation of FABP expression. The measured concentrations for FABP primary transcript were used as input into the computer simulation with the software STELLA II. Optimal fit between the simulated (solid line) and experimental data (data points from Haunerland et al., 1992) were obtained when using the following rates: FABP degradation: 0.02/day (half-life 34 days); mRNA degradation: 0.3/day (half-life 2.3 days); FABP synthesis $~$ FABP mRNA. Processing/transport is a saturable process, following Michelis-Menten Kinetics: $K_{M}=2000$ copies/ng RNA. Details see text.

assuming a protein half-life of 34 days (Fig. 7). Hence, locust FABP appears to be an extraordinary stable protein, a fact that is advantageous for maintaining the very high FABP levels found in fully differentiated flight muscles.

FABP levels increase from 0 to $18 \%$ of the total cytosolic proteins after FABP expression is turned on in adult locusts. The FABP concentration finally reaches a new steady state, where the gene is expressed at a rate needed to counteract FABP breakdown. Under steady state conditions of gene expression, the final concentration of a protein in the cell depends only on its stability (Hargrove and Schmidt, 1989). Theoretical considerations (Hargrove, 1993, 1994) revealed that half of the total shift in protein concentration between two steady states will have taken place after a time period that equals the half-life of the protein, and that induction will be $97 \%$ complete following a five times longer period. Therefore, if the FABP gene was expressed always at the very low rate seen in insects older than 2 weeks, ultimately the FABP concentration would reach the same maximal value. However, with an FABP half-life of 34 days, the final FABP concentration would be reached only after half a year, because a time period of approximately 5 half-lives is required to establish the new steady state. It is obvious that with the long half-life of locust FABP and the relatively short life time of the animals a rapid increase in FABP can only be achieved through transient, high levels of expression. Through the rapid accumulation of much larger concentrations of mRNA, the final FABP concentration is reached within 2 weeks. At that time, however, the mRNA concentration must be reduced to the maintenance level.

The variations in FABP mRNA are clearly a consequence of dramatic changes in the expression of the 
FABP gene. Indeed, the number of primary transcript molecules measured from day 2 to day 6 of adult life is extremely high. The synthesis rate of mRNA is halfmaximal at day 10 when the primary transcript concentration is similar to the $\mathrm{K}_{\mathrm{M}}$. From the simulation, the maximal rate is achieved between day 2 and 6 , when primary transcript is at least ten-fold higher. Obviously, a vast overshoot in the transcription of the FABP gene occurs at the earlier days, as a huge excess of primary transcript is produced here.

The results obtained in this study provide a plausible explanation for the observed changes in FABP gene expression. However, the fact that the simulation leads to results that are similar to the measured data does not prove that the current model is correct, as several assumptions have been made in the construction of the model. The proposed model does not consider possible changes in stability of either primary transcript or mRNA. However, such stability changes alone could not explain the observed data, unless multiple changes and extremely unlikely values were assumed. In contrast, the half-lives of mRNA and protein found here, while certainly long, are not unrealistic; mRNA half-lives of up to $100 \mathrm{~h}$ have been reported (Steward et al., 1985). The stability of FABP and its mRNA may be associated with the function of FABP as a free fatty acid transporter, as locusts need large amounts of FABP to acquire the ability to fly long distances thought their adult life. Proteins that are required in large concentrations and their mRNAs are frequently very stable, like the oxygen transporter hemoglobin. In murine erythroleukemia cells, $\beta$ globin mRNA can accumulate to values as high as $90 \%$ of total cellular mRNA. This high level can only be achieved because of the relative stability of globin mRNA, with a half-life of about 50 hours, and globin itself, which is stable in mature blood cells (Ross and Sullivan, 1985; Ganguly and Skoultchi, 1985). Hence, the high stability of FABP and its mRNA is not without a precedent, and is certainly advantageous from a physiological standpoint.

Locust flight muscle FABP is very similar in its primary and tertiary structure to mammalian muscle FABP, and its synthesis increases similarly in response to exercise or elevated lipid supply. Mammalian muscle FABP and its mRNA also increase during development, but only up to 3-fold over a period of several weeks (Heuckeroth et al., 1987). The total FABP concentration never exceeds the $6 \%$ found in rat heart (Veerkamp and Maatman, 1995). Apparently, a similar overshoot in FABP expression as observed for the locust is not necessary in mammals. The technique used in this study should prove useful for the measurement of transcription rates in mammalian muscle as well, particularly in response to exercise or other physiological stimuli. Such studies in insect and mammalian muscle may provide further insights into the regulation of muscle FABP genes.

\section{Acknowledgements}

This research was funded by a grant from the Heart and Stroke Foundation of Canada.

\section{References}

Broesemer, R.W., Vogell, W., Bücher, Th., 1963. Morphologische und enzymatische Muster bei der Entwicklung indirekter Flugmuskeln von Locusta migratoria. Biochem. Z 338, 854-910.

Carey, J.O., Neufer, P.D., Farrar, R.P., Veerkamp, J.H., Dohm, G.L., 1994. Transcriptional regulation of muscle fatty acid binding protein. Biochem. J 298, 613-617.

Celi, F.S., Zenilman, M.E., Shuldiner, A.R., 1993. A rapid and versatile method to synthesize internal standards for competitive PCR. Nucl. Acids Res. 21, 1047.

Chen, X., Haunerland, N.H., 1994. Fatty acid binding protein expression in locust flight muscle. Induction by flight, adipokinetic hormone, and low density lipophorin. Insect Biochem. Molec. Biol. 24, 573-579.

Chen, X., Wang, Z., Haunerland, N.H., 1993. Flight muscle fatty acid binding protein synthesis in juvenile and adult forms of the desert locust Schistocerca gregaria. Insect Biochem. Molec. Biol. 23, 337-343.

Chomczynski, P., Sacchi, N., 1987. Single step method of RNA isolation by acid guanidinium thiocyanate-phenol-chloroform extraction. Anal. Biochem. 162, 156-159.

Crabtree, B., Newsholme, E.A. 1975. Comparative aspects of fuel utilization and metabolism by muscle. In: Usherwood, P.N.R. (ed.), Insect Muscle. Academic Press, London, pp. 405-491.

Elferink, C.J., Reiners, J.J., 1996. Quantitative RT-PCR on CYP1A1 heterogeneous nuclear RNA: a surrogate for the in vitro transcription run-on assay. Bio Techniques 20, 470-477.

Ganguly, S., Skoultchi, A.I., 1985. Absolute rates of globin gene transcription and mRNA formation during differentiation of cultured mouse erythroleukemia cells. J. Biol. Chem. 260, 12167-12173.

Guglielmo, C.G., Haunerland, N.H., Williams, T.D., 1998. Fatty acid binding protein, a major protein in the flight muscle migrating Western Sandpipers. Comp. Biochem. Physiol., in press.

Hargrove, J.L., Schmidt, F.H., 1989. The role of mRNA and protein stability in gene expression. FASEB J 3, 2360-2370.

Hargrove, J.L., 1993. Microcomputer-assisted kinetic modeling of mammalian gene expression. FASEB J 7, 1163-1170.

Hargrove, J.L., 1994. Kinetic modeling of gene expression. R.G. Landes, Austin, $92 \mathrm{p}$.

Haunerland, N.H., 1994. Fatty acid binding proteins in locust and mammalian muscle. Comparison of structure, function, and regulation. Comp. Biochem. Physiol. 109B, 199-208.

Haunerland, N.H., 1997. Transport and utilization of lipids in insect flight muscles. Comp. Biochem. Physiol. 117B, 475-482.

Haunerland, N.H., Chisholm, J.M., 1990. Fatty acid binding protein in flight muscle of the locust Schistocerca gregaria. Biochim. Biophys. Acta 1047, 233-238.

Haunerland, N.H., Andolfatto, P., Chisholm, J.M., Wang, Z., Chen, X., 1992. Fatty-acid-binding protein in locust flight muscle, Developmental changes of expression, concentration and intracellular distribution. Eur. J. Biochem. 210, 1045-1051.

Heuckeroth, R.O., Birkenmeier, E.H., Levin, M.S., Gordon, J.I., 1987. Analysis of the tissue specific expression, developmental regu- 
lation, and linkage relationships of a rodent gene encoding heart fatty acid binding protein. J. Biol. Chem. 262, 9709-9717.

Marzluff, W.F., Huang, R.U.C.C., 1984. In: Hames, D.B., Higgins, S.F. (eds.), Transcription and translation: a practical approach. IRL Press, Oxford, pp. 89-129.

McCully, J.D., Liew, C.C., 1988. RNA transcription in myocardialcell nuclei during postnatal development, the study establishing an assay system for transcription in vitro. Biochem. J 256, 441-445.

Palmiter, R.D., 1973. Ovalbumin mRNA translation. J. Biol. Chem. 248, 2095-2106.

Pelham, H.R.N., Jackson, R.J., 1976. An efficient mRNA-dependent translation system from reticulocyte lysates. Eur. J. Biochem. 67, 247-256.

Quian, L., Vu, M.N., Carter, M., Wilkinson, M.F., 1992. A spliced intron accumulates as a lariat in the nucleus of $\mathrm{T}$ cells. Nucleic Acids Res. 20, 5345-5350.

Richter, J.D., Smith, L.D., 1981. Differential capacity for translation and lack of competition between mRNAs that segregate to free and membrane-bound polysomes. Cell 27, 183-191.

Ross, J., Sullivan, T.D., 1985. Half-lives of beta and gamma globin messenger RNAs and of protein synthetic capacity in cultured human reticulocytes. Blood 66, 1149-1154.
Sharp, P.A., 1994. Split genes and RNA splicing. Cell 77, 805-815. Steward, A.R., Wrighton, S.A., Pasaco, D.S., Fagan, B., Li, D., Guzelian, P.S., 1985. Synthesis and degradation of 3-methylcholanthrene inducible cytochromes P540 and their mRNAs in primary monolayer cultures of adult rat hepatocytes. Arch. Biochem. Biophys. 241, 494-508.

Van Der Horst, D.J., Van Doorn, J.M., Passier, P.C.C.M., Vork, M.M., Glatz, J.F.C., 1993. Role of fatty acid binding protein in lipid metabolism of insect flight muscle. Mol. Cell Biochem. 123, $145-152$.

Veerkamp, J.H., Van Moerkerk, H.T.B., 1993. Fatty acid binding protein and its relation to fatty acid oxidation. Mol. Cell Biochem. 123, 101-106.

Veerkamp, J.H., Maatman, R.G.H.J., 1995. Cytoplasmic fatty acidbinding proteins: their structure and genes. Prog. Lipid Res. 34, $17-52$.

Wang, Z., Chen, X., Haunerland, N.H., 1993. Flight muscle development in juvenile and adult forms of the desert locust Schistocerca gregaria. J. Insect Physiol. 39, 325-333. 